\title{
Introducing Magazines and/as Media: The Aesthetics and Politics of Serial Form
}

\author{
Faye Hammill \\ University of Strathclyde \\ Paul Hjartarson \\ University of Alberta \\ Hannah McGregor \\ University of Alberta
}

\section{The newness of periodical studies?}

In her recent book on the ongoing relationship between modernism and media, Jessica Pressman makes the convincing claim that modernism-as a "strategy of innovation that employs the media of its time to reform and refashion older literary practices in ways that produce new art"-is "centrally about media" (3-4 emphasis added). Pressman is not the first to link modernist aesthetic innovation to the rapid transformation of media technologies at the turn of the twentieth century; she identifies her indebtedness to media scholars including Friedrich Kittler, Lev Manovich, and Marshall McLuhan, all of whom engage with the new discourse networks afforded by the rise of phonographs, radio, and cinema. She also echoes the work of scholars like Ann Ardis, who argued in 2013 that the turn of the twentieth century is a period of "media in transition," characterized by a complex "media ecology" that demands "scrupulous attention to both the materiality of print and its intermedial relationships with other communication technologies" ("Towards" 1). While Pressman leaves it out, Ardis and many other scholars make a point of including the periodical press in this media ecology and as part of "the still broader field of 'print 
Faye Hammill is

Professor of English at the University of Strathclyde. Her research areas are

Canadian studies and early twentieth-century literature. She is author or co-author of five monographs, most recently Magazines,

Travel, and Middlebrow

Culture, with Michelle

Smith (2015). Her earlier book Sophistication: A Literary and Cultural History (2010), won the European Society for the

Study of English book award. She established the AHRC Middlebrow Network in 2008, and is an associate editor of the International Journal of Canadian Studies and former editor of the British Journal of Canadian Studies. culture studies,' a post-disciplinary re-orientation that Victorianists have staged very productively over the last ten to fifteen years" ("Towards" 2).

Debates over how periodicals mediate their content-and how we, as scholars, inevitably remediate them - have been a central tenet of the field since at least 1989, when Margaret Beetham pointed out that the archival practice of stripping out advertisements and binding periodical issues into volumes changes their meaning as objects of study (97). Similarly, Beetham's attention to television as a parallel medium, helpful for thinking through the dynamics of seriality, signals that media theory has long been central to the theorization of the periodical as a form. Thus, when Sean Latham and Robert Scholes announced in 2006 that the new field of "modern periodical studies" would be characterized by both an increased scholarly interest in periodicals as "autonomous objects of study" and the "still-emergent field['s] ... aggressive use of digital media" (517-18), their oft-cited article pointed both forward to a reinvigorating of the field and back to the field's long continuities.

Periodical studies - as a field that insists on the value of reading across full issues and multi-year runs of serial texts rather than cherry-picking individual items-has indeed benefited from the increase in large-scale digitization projects that make rare periodical titles widely available. The twenty-year-old Modernist Journals Project (MJP) (modjourn.org) is responsible for a variety of important initiatives, such as the digitization of full magazine runs that include advertising as well as covers-paratextual material often stripped away during the process of archivization and thus difficult to locate but central to our understanding of magazines as a medium. The MJP has been joined by a variety of other digitization initiatives. Even the briefest survey of these projects demonstrates their historical and aesthetic range. The UK-based Modernist Magazines Project (modernistmagazines.com) joined the rosters in 2006, followed in 2011 by The Pulp Magazines Project (pulpmags.org). Starting in 2009, the Chinese Women's Magazines project (womag.uni-hd.de) has been developing a database of popular women's magazines published between 1904 and 1937. In 2012 The Yellow Nineties (189os.ca) launched, offering open-access digital facsimiles of the "avant-garde aesthetic periodicals that flourished in Great Britain at the fin-de-siècle." Between 2011 and 2013 Magazines, Travel, and Middlebrow Culture in Canada 1925-1960 (middlebrowcanada. org) created a searchable catalogue derived from the tables of contents of selected Canadian middlebrow magazines; ${ }^{1}$ in 2014 Modern Magazines

1 The study of Canadian middlebrow periodicals emerging from this project, Magazines, Travel and Middlebrow Culture: Canadian Periodicals in English

\section{2 | Hammill, Hjartarson, McGregor}


Project Canada (modmag.ca) continued the work on Canadian household magazines by collaborating with the University of Alberta Libraries Digital Initiatives to digitize the complete thirty-two-year run of The Western Home Monthly, the largest single magazine digitization project to date. ${ }^{2}$

Digitization has also opened up new methodological possibilities for reading across massive multi-year archives, methodologies that take advantage of machine reading to compensate for the limits of human memory and time. In his introduction to the Journal of Modern Periodical Studies' special issue on "Visualizing Periodical Networks," J. Stephen Murphy explains that "The contributors to this issue share a common commitment to not-reading magazines, as well as to reading them," not because approaches such as data mining and network visualization offer a shortcut for lazy readers but because they can expose "relationships among data that would be otherwise obscured" (vii). Jeff Drouin's contribution to that special issue goes on to articulate the benefits of combining close and distant reading, or "micro and macro analysis" (111): "The point is not that digital methods in distant reading should replace traditional techniques, but rather that they should show us where to apply them or suggest answers where the print trail is inconclusive.... The computer shows us interesting patterns that can shape our inquiry, prompt us to ask new questions, and test assumptions" (130). Drouin's article also clearly explicates how digital methods have enabled a richer understanding of magazines as media rather than texts or repositories of historical information. Drawing on Sean Latham's essay, "Unpacking My Digital Library: Programming Modernist Magazines" (forthcoming), Drouin explains that magazines are characterized by emergence, "a particular kind of complexity that arises not from the individual elements of a system, but only from their interaction" (Latham, quoted in Drouin 113). The process of reading a magazine involves actively assembling the different components-articles, advertisements, illustrations, letters to the editor-into an unpredictable, idiosyncratic, and ultimately unstable whole. With its capacity for reading across large quantities of text in non-linear ways and discovering unlikely patterns, distant reading is a promising method for capturing this quality of emergence and thus for better understanding the unique properties of magazines as media.

and French, 1925-1960, models the kinds of periodical scholarship that emerges at the intersection of media studies and literary studies; see Hammill and Smith.

2 For a discussion of the process of digitizing a periodical archive, and its impact on scholarly understandings of the periodical as a medium, see McGregor.
Paul HJartarson is Professor Emeritus in English and Film Studies at the University of Alberta, where he leads the Editing Modernism in Canada research group (EMiC UA). His most recent book, co-authored with S.C. Neuman and EMiC UA, is The Thinking Heart: The Literary

Archive of Wilfred Watson (UAP 2014). The Thinking Heart served as the catalogue for an exhibition of Watson's literary papers held in the Bruce Peel Special Collections Library, University of Alberta from October 2014 to January 2015. 


\section{HanNah McGregor}

is a SSHRC-funded

postdoctoral fellow

in English and Film

Studies at the University of Alberta, where her

research focuses on

media studies, Canadian

literature, and digital

humanities. Part of the

EMiC UA research group, her postdoctoral project,

Modern Magazines

Project Canada

(modmag.ca), explores new methods for reading

digitized periodical archives, with a focus on the Winnipeg-based magazine The Western

Home Monthly (1899 to 1932). Her work has been published in Archives \& Manuscripts, University of Toronto Quarterly, Canadian Literature, and the International Journal of Canadian Studies.
These digitization projects, alongside the methodologies and findings to which they have led, are excitingly new, offering not only access to previously marginalized materials but also new ways of reading familiar texts. That exciting newness, however, poses its own dangers. First, we risk forgetting that the history of periodical studies has been a history of studying mediations and their remediations. From Beetham's questioning of what is lost when periodicals are bound into volumes to recent scholars' worries about the "offline penumbra" of magazines that are not digitized, new technologies of preservation bring both losses and new possibilities for studies. Perhaps the greatest risk, as Maria DiCenzo argues in this issue's opening essay, is the "rhetoric of newness" itself, with its "self-reinforcing narratives about emergence and innovation," and the disciplinary blindness that results:

the effect of ahistorical approaches to the criticism (of looking only forward and not back) is to miss or dismiss decades of valuable scholarship. In order not to keep starting from scratch, it is important to highlight the longer history and discourage the idea that period-and discipline-specific or nationallybased studies might preclude our interest. (23-24)

As we argued above, the field of periodical studies is characterized by marked continuities-continuities that have been ill served by the disciplinary boundaries that have siloed and divided periodical scholars.

This special issue, and its Journal of Modern Periodical Studies companion issue (JMPS 6.2), strive to highlight these continuities, celebrating what is innovative in recent turns in periodical studies while paying heed to the field's long history. In 1989, Laurel Brake and Anne Humphreys pointed out the need to start theorizing periodicals, to stop " 'using', more or less uncritically, selected parts of the Victorian periodical press as reflections of readership, attitudes, and responses" (94). That this same point had to be made at the announcement of "modern periodical studies" in 2006 says much about how periodical studies has suffered from a lack of communication across fields. It is for this reason that we, the editors, strive to contribute to a body of work that bridges the "great divides" Ann Ardis has identified in this field:

the divide between all things "Victorian" or "traditional" and all things "modern" or "modernist" (with the former often construed reductively to privilege the newness of twentiethcentury artistic and cultural phenomena); the divides between

\section{4 | Hammill, Hjartarson, McGregor}


both "literature" and what Laurel Brake has termed the "subjugated knowledges" of journalism and between high and low culture; and the divide between art (or modernist high seriousness, more particularly) and everyday life. ("Editor's Introduction" v-vi)

The variety of periodicals discussed across the twelve articles in these special issues range from the 1870 s to the 1940s, from Britain to Canada to the U.S. to Australia, from pulp to middlebrow to avant-garde, and the methodological approaches are accordingly, and appropriately, diverse. In fact, the sheer diversity of approaches invites another question central to the field: whether periodical studies needs consolidation as a field or if its strength lies in its heterogeneity and interdisciplinarity. These joint special issues can be read as an experiment in finding sites of exchange across disciplinary, geographical, and chronological boundaries, united by our interest in reading periodicals through, as, and alongside media.

\section{Periodical studies as media studies}

In the opening essay of the JMPS companion issue, Patrick Collier asks whether a thing called "modern periodical studies" exists and turns to the field's journal-the very one in which his essay appears-to find an answer to that question. Appearing in the digital pages of the very journal that articulates the existence of such a field, this question may seem purely rhetorical. It is certainly timely: a moment of pause five years after the journal's establishment to consider what the concretion of energy and scholarly attention around this field has wrought. Collier's question echoes the MLA 2013 roundtable that was in many ways the starting point for these special issues, although the editors were mere audience members. Organized by J. Stephen Murphy around the similarly evocative question "What Is a Journal?," the roundtable began from the premise that periodical studies was fragmented due to the absence of a unified theoretical framework-a move toward synthesis that, while important, is not new.

The conversations at that roundtable strongly emphasized the importance of reading magazines within networks of mediation and remediation. While Ardis argued for a media ecology perspective that understands periodicals' "intermedial relationships with other communication technologies" ("Towards" 1) and Sean Latham insisted that we start "thinking about [modern magazines] as new media technologies," James Mussell articulated directly the call for a methodological turn shaped by attentiveness to "the way media mediate" ("Matter" 4). Specifically, Mussell emphasized the importance of sameness and repetition within media. This concern

\section{These joint}

special issues

can be read as

an experiment

in finding sites

of exchange

across

disciplinary,

geographical,

and chronologi-

cal boundaries,

united by our

interest in

reading

periodicals

through, as, and alongside media. 
resonates with our sense that periodical studies is frequently structured by an implicit hierarchy of content that privileges the story over the advertisement, the enduring over the fashionable, or, more broadly, the exceptional over the repetitive. It was our desire to carry on this conversation that led to the organization of "Magazines and/as Media: Methodological Challenges in Periodical Studies," a three-day workshop held at the University of Alberta, 14-16 August 2014.

The presentations and discussions at this workshop took up the MLA panel's exhortations to think through magazines and their relation to media in two distinct but related ways. They considered, first, how magazines, whether as new media or the transitional remediation of old media, relate to the other media forms that shaped the cultural production and circulation of the late-nineteenth and earlier-twentieth centuries, including photography, radio, and film. Second, they asked how the advent of digital technologies opens new methodological avenues for engaging with periodicals" "vast and unwieldy archives" (Latham and Scholes 529). We were particularly interested in exploring methodologies and critical perspectives that resisted the privileging of canonical objects of study-such as high modernist literary production-in favour of understanding magazines as miscellany, as database, or as network, all metaphors that emphasize patterns of repetition, interlocking systems of mediation, and a certain ludic interplay of objects that resist easy differentiation and categorization.

The resulting special issues strive to find common approaches by exploring the ways in which various scholars' work generates productive tensions via differing conceptions of the magazine as object of study. The papers collected here and in the companion issue, JMPS 6.2, are committed to examining magazines as material objects and locating those objects in history, which also entails understanding them as a form of technology in transition. This focus on magazines and/as media demands a shift beyond the modernist little magazine to explore pulp and glossy and amateur periodicals and beyond Victorian literary periodicals to examine digests, newspapers, and newsletters as vital forms of media production. Challenging the restrictive norms of discipline and brow, these special issues also strive to span a range of historical periods and geographical locales to offer a genuinely border-crossing conversation.

Despite the diversity of understandings of what a periodical is, there are a few features that unify this field through a shared object of study. Periodicals are print media characterized by both seriality-single titles are instantiated across multiple issues-and periodicity—titles strive for,

\section{6 | Hammill, Hjartarson, McGregor}


if they don't always achieve, a regular circulation cycle that structures reader engagement. As Mussell has argued elsewhere:

No single issue [of a periodical] exists in isolation, but instead is haunted by the larger serial of which it is a part. This larger serial structure is invoked through the repetition of certain formal features, issue after issue. It insists on a formal continuity, repeated from the past and projected onwards into the future, providing a mediating framework whose purpose is to reconcile difference and present it in a form already known to readers. The new, whether it is the next instalment of a story, a one-off essay on a new subject, or a piece of news, is always tempered, regulated within a formal framework that readers have seen before. ("In Our Last" forthcoming)

The continuity of a title, despite the almost complete absence of repeated content from issue to issue, depends upon the magazine's function as a medium. A key characteristic of how a periodical mediates its content is, perhaps self-evidently, its periodicity. As Mark W. Turner has explained, the patterns of periodicity established by the emergence of the periodical press in the nineteenth century are central "not only ... for understanding the press, but also for understanding the emergence of modern culture and the history of modernity" (183). The periodical press was both one of the innovations of modernity that reflected shifting understandings of time and of the "schedules and patterns [that] shape ... everyday life" and a source of the anxiety that accompanied those shifts (187-88). The periodicity of the periodical press, after all, was anything but regular. Daily newspapers, weekly and monthly magazines, and semi-annual or annual reviews competed with one another for readerly attention, resulting not in the kind of mechanized rhythm linked with modern time but in what Turner calls "cacophony" (192).

Periodicity might be described as one of the "protocols" that Lisa Gitelman attributes to media, part of that "vast clutter of normative rules and default conditions, which gather and adhere like a nebulous array around a technological nucleus" (7). While the materiality of media is central to their operation-as J. Matthew Huculak's essay in our companion special issue on paper production and little magazines makes clear-the normative rules of their use must also be grasped. In addition to periodicity, information such as subscription rates and policies, advertising, circulation networks, and reading habits are key to theorizing periodicals as media. And yet this information can be remarkably difficult to capture when approaching historical texts, especially when archival practices 
have ignored exactly what scholars today find most interesting. Periodical scholars are finding ways around these problems. Will Straw, Andrea Hasenbank, and Kirsten MacLeod are collectors and curators of their own objects of study, gathering materials that institutions have not traditionally thought worthy of archiving. Scholars like Lorraine Janzen Kooistra have responded to the absence of resources by creating their own digital tools and repositories. And yet some information will remain out of reach. The issue Murphy raises concerning readers of serialized novels can be extended to the reading of periodicals themselves: "The great question that remains unanswered for us today is just what the experience of those readers ... of any serialized novel was. In other words, what was it like to read a serialized novel in an era when it was a publishing norm?" (184). He proposes to answer that question by using the classroom as a laboratory in which students read novels in serial form and reflect on the experience, a fascinating approach that acknowledges rather than resisting the inaccessibility of historical reading experiences.

Other periodical scholars handle the problem of the reader in a variety of ways. Mussell responds by focusing on the rhythms of periodical production explored and exploited by one notorious periodical producer. He explains that "Seriality was part of the way these publications slotted into the lives of readers, coming to hand at convenient moments while also helping provide the rhythms that structured everyday life" (72). Debra Rae Cohen, on the other hand, uses the BвC's Listener as a site for the exploration of competing protocols of readership and listenership, denaturalizing the experience of reading a magazine by teasing out the activity's connection to listening to pre-World War II radio programming. In contrast, Andrea Hasenbank in this issue, and Jana Smith Elford in the JMPS companion issue, are interested in the reader as a node in a network-a complex relationship among texts, producers, and readers in which periodicals participated and which periodicals might, through careful analysis, reveal. The genres of the review journal and the newsletter are both ideal subjects for network analysis, as they point toward how periodicals can work to inscribe the very communities that their regular circulation also helps bring into being. And yet, as Will Straw points out, readerships will sometimes be "impossible to reconstruct-not simply because too much time has elapsed, but because the tokens that normally serve to specify readers (advertisements other than those for in-house publications, letters to the editor, references elsewhere in popular culture to the reading of these periodicals) are virtually non-existent" (JMPS companion issue). The fantasy of total historical reconstruction is sometimes just that.

\section{8 | Hammill, Hjartarson, McGregor}


Similarly, digital remediation as an approach begins from the acknowledgement that the perfect reclamation of the historical object may be an impossibility. As Mussell argues, the archived collection of print magazines is already remediated, and the further remediation of print archives into digital forms can in fact increase our understanding of periodicals: "What appears to be a deficit, a misrepresentation, in digital resources, is actually difference, introduced through transformation. By making them strange, digital resources demonstrate how much more there is to know about print and print culture" ("In Our Last" forthcoming). Latham shares this perspective, exploring in his work how digitization might expose something fundamental about the periodical as a medium that its print form paradoxically makes hard to discover:

Magazines share a great deal with digital culture and particularly with the modalities of hypertext, in which documents are linked in a non-hierarchical way.[...] Thus a single article might be flattened out and scattered across one or many issues, its columns of text jostling with illustrations (typically unseen and unapproved by authors), commentary, and advertisements. Readers are thus freed to break the linear structure of most narrative texts and see on the dynamic pages of a magazine what N. Katherine Hayles calls the "recombinant flux" we now associate primarily with digital textuality. ("Mess and Muddle" 410)

When Cohen warns about the potentially "originist" implications of this argument, which risks claiming that digital remediation might recreate the original relationship between periodical and reader, her critique is apt (98). As part of her warning, she calls for-and models-greater attention to how periodicals were themselves highly intermedial objects, in conversation with the surrounding media landscape of the day and frequently remediating the competing temporalities or periodicities of other media such as radio.

Remediation and intermediality are central terms for this special issue, and for a media studies approach to periodicals as well as to book history. ${ }^{3}$ Perhaps the most familiar definition of remediation comes from Jay David Bolter and Richard Grusin's book of the same name, in which they define remediation as "the representation of one medium in another" (45) and the dialectic between old and new media that results (50). New media, they

3 In July 2015, for instance, a symposium at the University of Edinburgh, titled Books and/as New Media, took up remediation and intermediality in the context of the history of the book in the eighteenth and nineteenth centuries. 
explain, is equally preoccupied with both immediacy and hypermediacy, that is, "the transparent presentation of the real" on the one hand and "the enjoyment of the opacity of media themselves" on the other (21). Gitelman further explains that successful media must obscure their own mediation "in favour of attention to the phenomena, 'the content" of the thing (6). Periodicals have arguably done a very good job of rendering themselves immediate, or, more accurately, we have done a very good job of imagining periodicals as immediate, if reading approaches that pluck periodical content out of its context are any indication. And yet, as Cohen's, Janzen Kooistra's, and Kuttainen, Liebich and Galletly's articles indicate, periodicals were themselves dense with the remediation of old and new media, from radio to film to woodcuts, creating a level of hypermediacy that is lost to our analysis unless we relocate periodicals in their contemporary media ecologies. Intermediality, or the interaction and interconnectedness of multiple contemporary media, is a central feature of the modern periodical, as it interacted with, incorporated, and contested other media platforms. Kuttainen, Liebich, and Galletly turn to Madianou and Miller's concept of polymedia "as a way to understand the use of, and relationship to, multiple platforms of media in interpersonal communication" particularly in terms of "the relationships users develop through and with different media forms" (160, 161). Media are, after all, affectively charged modes of communication, as much as they are material instantiations of information and the protocols that regulate circulation and use.

Collier notes that the field of modern periodical studies is riven by implicit, although rarely stated, dissent over "what the object of knowledge is in modern periodical studies" (JMPS companion issue). The papers in the JMPS special issue take up his provocation by testing a variety of answers: is the periodical a serial system that produces social action through codified genres or is it a circulating media object capable of carrying materials across spaces both social and geographical? Is it a material instantiation of the multiple nodes in a social network or a paper product that taps into transatlantic circuits of colonial exploitation and commodity exchange? Collectively, these papers articulate the fundamental interdisciplinarity of periodical studies, revealing how the very contention over our object of study is what allows the periodical to cut across disciplinary borders. The papers gathered in this special issue, on the other hand, were chosen for the way their individual case studies illuminate what is at stake both theoretically and politically in our understanding not just of what a periodical is but of how it operates.

10 | Hammill, Hjartarson, McGregor 


\section{Reading serial form}

We have thus far traced a number of features that periodicals, as part of a modern media ecology, have in common, including seriality, periodicity, and intermediality. Perhaps even more central to the study of periodicals - and to their interest as objects of study - is the kind of unpredictable and exciting juxtapositions that occur within and across their pages, the inclusion of "literary materials and cultural materials (theater reviews, book reviews, etc.) within the rich context of economic writings, political writings, notes on meetings and political strategies, investigative journalism, interviews, histories, polemical writings, essays on fashion, cartoons, and other materials" (Green 192). As Barbara Green goes on to explain, this juxtaposition was far from apolitical. In fact, the rise of the periodical press in the late nineteenth century was so intertwined with the New Woman phenomenon that anxieties about shifting gender roles were often conflated with critiques of new genres of journalism (194). Similarly, the commercialization of the periodical press, including the adoption of advertising policies that were able to drastically reduce issue prices and thus increase readerships, "was closely associated with the emergence of the woman reader" and sometimes derided as a sign of the feminization, and thus degradation, of the press (195).

Both the suffrage press and mass-market women's magazines had, in their different ways, a transformational effect on the histories of women, and, as a consequence, scholars of feminist and gender studies have made a major contribution to periodical studies. But this context, of course, is not the only one in which periodical form can be read politically. In Collier's "Imperial/Modernist Forms in the Illustrated London News," he concludes that "the image-collages of the Illustrated London News and the shaped and gathered fragments of The Waste Land" are two versions of the same formal attempt to engage with the "centralized, comprehensive gaze" of Empire; while the former articulates imperialism's ability to "keep a fragmented world in order," modernist aesthetics, disillusioned by the failure of the imperial vision, turn the fragment into "a purely aesthetic form" (510). In Collier's reading, the fragmented form of the periodical is saturated with both aesthetic and political meaning-an argument that runs through this special issue. The periodical's fragmentation, like the rich juxtaposition of genres to which Green draws attention, are thus not neutral understandings of the periodical form but charged with political concerns - of gender, class, race, and empire.

Collectively, the papers in this special issue work toward theorizing the aesthetic and political dimensions of reading periodical forms through 


\section{By bringing}

\section{these case}

\section{studies together,}

we insist on a

reorientation of

periodical

studies that

moves past the

accepted canons

and

\section{bibliographies}

and shifts

beyond the

familiar

cosmopolitan

centres. case studies that delve into the enormous diversity of periodical production. Beginning with DiCenzo's argument that periodical studies must remember its past rather than being overhasty to fetishize the new, this issue moves back and forth between the Victorian and the modern to articulate the continuities of concerns between these often bifurcated periods. Of particular interest is the periodical's capacity to produce publics and counterpublics via its rhythms of serialization, patterns of mediation and remediation, and production of alternative historiographies. Rachael Schreiber, in her introduction to Modern Print Activism in the United States, describes the expansion of the radical press alongside the mainstream press over the course of the late nineteenth and twentieth centuries: "With the availability of industrialized printing methods, newspapers, magazines, broadsides, and other forms appeared, using text and image to give voice to a wide range of people and, equally important, connecting readers to these authors and to each other.[...] [S] uch publications contributed to the formation of alternate and counter public spheres whose members imagined themselves as part of larger collectives" (3). Some of the essays in her volume focus on publications affiliated to specific causes-the Reform Press of the late nineteenth century, the suffrage press, Ku Klux Klan publications, Communist pamphlets, gay and feminist magazines. But mainstream consumer publications, too, could advance particular causes, and therefore, the collection also contains essays on the meaning of Mother's Day in Good Housekeeping and on the Cold War in the Ladies' Home Journal. Our special issue ranges similarly widely, from tiny bibelot magazines to mass-market consumer titles, from radical papers to art journals, emphasizing the sheer range of print production that falls within the category of the periodical to the point of testing that category's limits. The construction of cultural value is also a political act, and these different types of periodical align themselves with different cultural strata not only through their visual and stylistic choices but also through their intermedial engagements. By bringing these case studies together, we insist on a reorientation of periodical studies that moves past the accepted canons and bibliographies and shifts beyond the familiar cosmopolitan centres, while also demonstrating the exciting juxtapositions that emerge not only between diverse items on the periodical page but also between studies of diverse periodicals.

Positioning herself as an unplugged-inclined historian of women's media and early feminist movements, Maria DiCenzo opens this issue with a discussion of what is at stake in the digital turn in periodical studies and what cultural values we are implicitly adopting through the creation

12 | Hammill, Hjartarson, McGregor 
of an "off-line penumbra." "As long as the 'past' remains a site of contention," she argues in "Remediating the Past: Doing 'Periodical Studies' in the Digital Era,"

the periodical press will be relevant to historiographical debates and much of this research will continue to take the form of "samplings and soundings" combined with attempts at comprehensive and synthetic analyses. Periodicals produced as part of early reform campaigns or social movements, and by marginalized and oppressed groups, are not likely candidates for digitization on a large scale, so detailed critical studies are crucial to making them visible. If the focus on the discursive dimension of media does not seem strikingly new, the findings are. (35)

While engaged in such nondigital analysis, she contends, "it is possible to acknowledge the methodological challenges, by being reflexive about, rather than by effacing, the systems of value at work" (35-36). Arguing that "Periodicals offer rich opportunities to engage critically and productively with the tensions between analog and digital skills" (35), DiCenzo convincingly makes the case for "preserving non-digital skills and methods" and for ensuring that the periodical press of marginalized and oppressed groups will be visible to new generations of readers (34).

In "American Little Magazines of the 1890 os and the Rise of the Professional-Managerial Class," Kirsten MacLeod challenges our understanding of the category and history of "little magazines." She focuses her analysis on the more experimental, amateurish form of little magazines-also known as "fad magazines" or "fadazines" - published in the United States in the 189os. "Although these publications took their place alongside mass-market periodicals on the newsstands," MacLeod observes, "they presented themselves as defiantly different from mainstream magazines in various respects" (42). Arguing that these magazines have suffered scholarly neglect, she engages in an act of recovery. The strength of the essay lies in its threefold challenge to periodical studies: to the ongoing neglect of these fad magazines by periodical scholars, to our understanding of the networks such periodicals organize, and to amateur magazines themselves as a material social practice.

The faddish, the fashionable, and the novel are central to periodical culture. Seriality, James Mussell argues in "'Of the making of magazines there is no end': W. T. Stead, Newness, and the Archival Imagination," is structured by a tension between novelty and stability, the excitement of the new issue balanced by the steadily accumulated archive of past issues. 
"[M]agazines, like all serials, are predicated on repetition," he explains, "where novelty is tempered by formal features such as layout, typeface, certain features or articles, even the recurrence of the name itself" (70). As he explores Stead's manipulation of the affordances of the periodical, particularly competing rhythms of seriality, Mussell underlines the link between the periodical press and shifting understandings of journalistic practice and public discourse, culminating in the fantasy of "a simultaneity, a ubiquitous nowness, that Stead, like many of his contemporaries, dreamed about but never achieved" (87).

This question of competing media rhythms is also central to Debra Rae Cohen's “'Strange Collisions': Keywords Toward an Intermedial Periodical Studies," which uses the example of the BвC's weekly journal the Listener to ask how periodical studies might engage more rigorously with the media ecologies of the past. This periodical, she argues, is a "limit case, a visible instantiation of a generally occluded process" that "offers a hint of how we might think backward from our contemporary concentration on transmedial storytelling to historicize and formally describe an earlier version of convergence culture, one in which the periodical played an essential role" (102). Through meditations on three keywords-ergodic, flow, and sociability - her article insists that more formal considerations of media's properties must remain engaged with the publics those media hailed and the postures of reading and/or listening they encouraged.

In "The Politics of Ornament: Remediation and/in The Evergreen" Lorraine Janzen Kooistra, co-editor of The Yellow Nineties Online, reflects on the digital transformation of a print periodical into electronic textuality while "focusing on the specific editorial problem of periodical pages decorated with textual ornaments" (105). As her case study, she takes the work of The Yellow Nineties Online research group in digitally remediating the fin-de-siècle Scottish magazine, The Evergreen: A Northern Seasonal (1895 to 1897). Because The Evergreen made "remediated Celtic ornament a structural feature of its aesthetic design and an integral expression of its larger political agenda," Janzen Kooistra argues, digitizing and encoding these aesthetic devices lays bare "what is at stake if our own electronic remediation practices are not adequate to the periodical objects we study" (105).

Rather than an act of remediation, Andrea Hasenbank, like Kirsten MacLeod, is engaged in an act of recovery. In "Assembly Lines: Researching Radical Print Networks," her objects of study are the radical print publications - newspapers, magazines, pamphlets, and other ephemeraproduced in Canada in the 1930s. Although "Assembly Lines" is concerned

14 | Hammill, Hjartarson, McGregor 
with a range of such publications, it focuses on the Canadian Labour Defender (CLD), a periodical launched by the Canadian Labour Defence League in May 1930 as a monthly mimeographed newsletter. Within the $C L D$ itself, Hasenbank focuses on "a set of reviews of co-circulating periodicals and pamphlets published in the Defender through 1932 and 1933 " (132). An analysis of those reviews, she argues, reveals "the dense network of writers, artists, organizations, and labourers who worked to produce these forms of print" (132). Hasenbank argues that the CLD is an ideal site "for both bibliographical recuperation and network analysis of these groups" (132).

The final essay in this collection, Victoria Kuttainen, Susann Liebich, and Sarah Galletly's "Place, Platform, and Value: Periodicals and the Pacific in Late Colonial Modernity," concentrates on mainstream travel and leisure magazines from Australia and the west coast of the U.S., exploring the visions of the Pacific that they presented and their role in constructing hierarchies of cultural value. In conversation with "a larger project that considers the geographical imaginaries of various interwar periodicals, with a focus on the Pacific," this essay draws on magazines "as illustrations of how the negotiation of cultural value and media hierarchy intersects with this space" (158). Framed using the concept of "polymedia," their discussion considers the magazines as host platforms for a variety of other media, looking particularly at the way they reviewed and reported on contemporary films and fiction about the Pacific region. Kuttainen, Liebich, and Galletly "maintain that periodicals are particularly valuable as intermedial technologies" (173) that both register shifting political and cultural values and participate in the ongoing mediation and remediation of a complex and contested modernity.

Uniting these diverse papers is a commitment to reading magazines not as transparent containers of information but, rather, as complex media artifacts whose relation to their cultural and political contexts is articulated through rhythms of seriality, patterns of remediation, and material systems of production and circulation. Like the Journal of Modern Periodical Studies companion issue, this special issue is committed to locating periodical studies at the interstices of a variety of fields, methodologies, and historical periods. Our goal is not to synthesize but to juxtapose. These papers, while focusing on a heterogenous set of case studies, reveal the emergence of a shared critical discourse and a shared set of methods for reading periodicals as, and in relation to, media. 


\section{Acknowledgements}

The editors would like to thank the many collaborators and sponsors who made these joint special issues, and the workshop that inspired them, possible: our inimitable research assistant, Clare Mulcahy; at ESC, Michael O'Driscoll, Mark Simpson, and Sylvia Vance; at JMPS, Sean Latham and Mark Morrison; the Social Sciences and Humanities Research Council of Canada; the University of Alberta Libraries Digital Initiatives; the University of Strathclyde; the Royal Society of Edinburgh; the Kule Institute for Advanced Study; James Cook University; Eighteen Bridges magazine; the Alberta Magazine Publishers Association; the Canadian Literature Centre; and the University of Alberta Faculty of Arts.

\section{Works Cited}

Ardis, Anne. "Editor's Introduction. Mediamorphosis: Print Culture and Transatlantic/Transnational Public Sphere(s).” Modernism/modernity 19.3 (2012): v-vii. Web.

- "Towards a Theory of Periodical Studies." What is a Journal? Towards a Theory of Periodical Studies. MLA Convention 2013, Special Session 384. Web. 21 December 2012.

Beetham, Margaret. "Open and Closed: The Periodical as a Publishing Genre." Victorian Periodicals Review 22.3 (1989): 96-10o. Web.

Bolter, Jay David, and Richard Grusin. Remediation: Understanding New Media. Cambridge: MIT Press, 2000.

Brake, Laurel, and Anne Humphreys. "Critical Theory and Periodical Research.” Victorian Periodicals Review 22.3 (1989): 94-95. Web.

Collier, Patrick. "What is Modern Periodical Studies?" Magazines and/ as Media: Periodical Studies and the Question of Disciplinarity. Eds. Hannah McGregor, Paul Hjartarson, and Faye Hammill. Special issue of Journal of Modern Periodical Studies 6.2 (2015). Forthcoming.

- . "Imperial/Modernist Forms in the Illustrated London News." Modernism/modernity 19.3 (2012): 487-514. Web.

Drouin, Jeffrey. "Close- and Distant-Reading Modernism: Network Analysis, Text Mining, and Teaching The Little Review." Visualizing Periodical Networks. Ed. J. Stephen Murphy. Special issue of Journal of Modern Periodical Studies 5.1 (2014): 110-35. Web. 
Gitelman, Lisa. Always Already New: Media, History, and the Data of Culture. Cambridge: MIT Press, 2008.

Green, Barbara. "The Feminist Periodical Press: Women, Periodical Studies, and Modernity." Literature Compass 6.1 (2009): 191-205. Web.

Hammill, Faye, and Michelle Smith. Magazines, Travel, and Middlebrow Culture: Canadian Periodicals in English and French, 1925-1960. Liverpool: Liverpool UP, 2015.

Latham, Sean. "Affordance and Emergence: Magazine as New Media." What is a Journal? Towards a Theory of Periodical Studies. MLA Convention 2013, Special Session 384. Web. 21 December 2012.

- "The Mess and Muddle of Modernism: The Modernist Journals Project and Modern Periodical Studies." Tulsa Studies in Women's Literature 30.2 (2011): 407-28. Web.

—. "Unpacking My Digital Library: Programming Modernist Magazines." Editing Modernisms in Canada. Eds. Colin Hill and Dean Irvine. Toronto: University of Toronto Press, 2015. Forthcoming.

- and Robert Scholes. "The Rise of Periodical Studies." PMLA 121.2 (2006): 517-31. Web.

McGregor, Hannah. "Remediation as Reading: Digitising The Western Home Monthly." Archives and Manuscripts 42.3 (2014): 248-57. Web.

Murphy, J. Stephen. "Introduction: 'Visualizing Periodical Networks.” The Journal of Modern Periodical Studies 5.1 (2014): iii-xv. Web.

— . "The Serial Reading Project." Journal of Modern Periodical Studies 1.2 (2010): 182-92. Web.

Mussell, James. "'In Our Last': The Presence of the Previous in Periodical Form." Ms. courtesy of the author. Forthcoming in Victorian Periodicals Review. 2015.

—. "The Matter with Media." What is a Journal? Towards a Theory of Periodical Studies. MLA Convention 2013, Special Session 384. Web. 21 December 2012.

Pressman, Jessica. Digital Modernism: Making it New in New Media. Oxford Scholarship Online, 2014. Web. 21 November 2014.

Schreiber, Rachel. Introduction. Modern Print Activism in the United States. Ed. Rachel Schreiber. Farnham: Ashgate, 2013. 1-14. 
Straw, Will. "Constructing the Canadian Low-Brow Magazine: The Periodical as Media Object in the 1930s and 1940s." Magazines and/ as Media: Periodical Studies and the Question of Disciplinarity. Eds. Hannah McGregor, Paul Hjartarson, and Faye Hammill. Special issue of Journal of Modern Periodical Studies 6.2 (2015). Forthcoming.

Turner, Mark W. "Periodical Time in the Nineteenth Century." Media History 8.2 (2002): 183-96. Web. 